\title{
Accidental Bladder Injury during Elective Repair of a Strangulated Inguinal Hernia: A Preventable Complication with High Morbidity
}

Dr. Ettahiri Soumeya, Dr. Ezzaki Houda, Dr. Souiki Tarik, Dr. Ibn Majdoub Karim, Dr. Toughrai Imane, Dr. Mazaz Khalid

Department of General and Visceral Surgery, Hassan II University Hospital of Fez, 30050, Fez, Morocco

DOI: $\underline{10.36347 / \text { sasjs.2022.v08i01.009 }}$

| Received: 11.12.2021 | Accepted: 16.01.2022 | Published: 23.01.2022

*Corresponding author: Dr. Ettahiri Soumeya

Department of General and Visceral Surgery, Hassan II University Hospital of Fez, 30050, Fez, Morocco

\section{Abstract}

Case Report

Urinary bladder injury is usually rare and asymptomatic, and can occur during herniorrhaphy for misdiagnosed sliding hernia. It's necessary to recognize a iatrogenic injury intra operatively, and institute treatment in the same operative session, Preoperative diagnosis can prevent possible to the bladder and ureter surgery and lead to quick recovery. The radiological examination is needed before any surgery, especially when the patient has concomitant urinary symptoms. If bladder hernia is suspected, we should imperatively perform preoperative radiology including ultrasound cystography, CT scan or MRI. Keeping a bladder catheter in situ can alert the surgeon in the event of bladder surgery.

Keywords: Bladder hernia, inguino scrotal hernia repair, retrograde cystography.

Copyright $\odot 2022$ The Author(s): This is an open-access article distributed under the terms of the Creative Commons Attribution 4.0 International License (CC BY-NC 4.0) which permits unrestricted use, distribution, and reproduction in any medium for non-commercial use provided the original author and source are credited.

\section{BACKGROUND}

Inguinal hernia is a very common surgical disease world-wide. A sliding hernia is a type of hernia in which the contents one portion of a body cavity extends with the hernia sac into another body cavity. In a sliding bladder hernia, the urinary bladder herniates with the inguinal sac itself. [1] The main signs are : irreducible mass in the inguinal area, accompanied by urinary symptoms like urinary retention, difficulty with urination, and intermittent stages of urination, and this also can lead to severe complications as bladder incarceration and necrosis, bladder hemorrhage, obstructive bladder dysfunction, and even renal failure $[1,2]$.

\section{PRESENTATION OF CASE}

A 69 year old man was reffered to the emergency department of our surgical facility in may 2019 with abdominal pain and large inguino scrotal swelling hernia that appeared one week ago, he had no abnormalities and no surgical history, the examination revealed an inguinal hernia that extended to the scrotum that was non-reductible.
We didn't do any radiology examinations. The patient underwent an open pre-peritoneal inguinal herniorrhaphy and the bladder was reduced with an injury to the bladder wall.

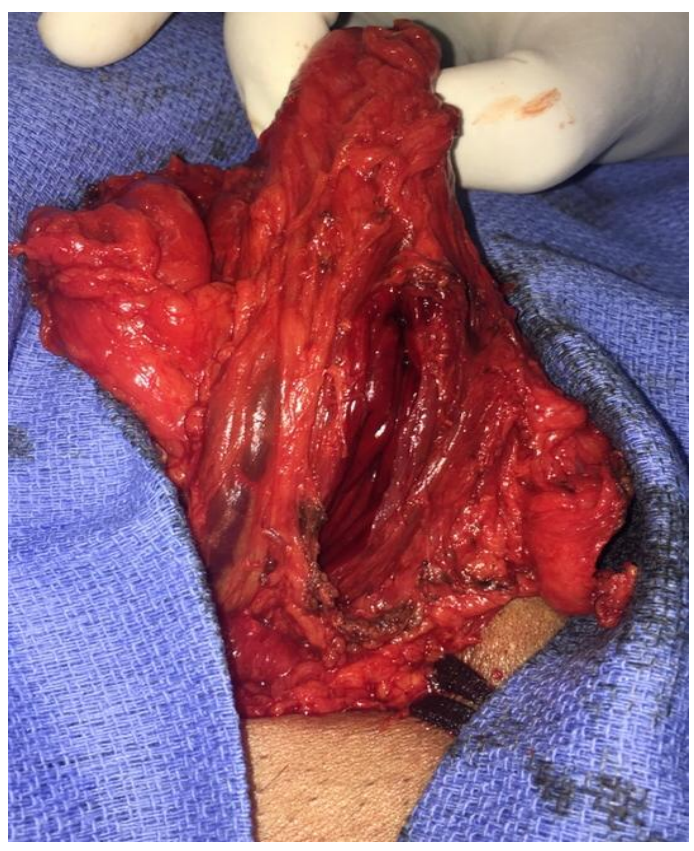




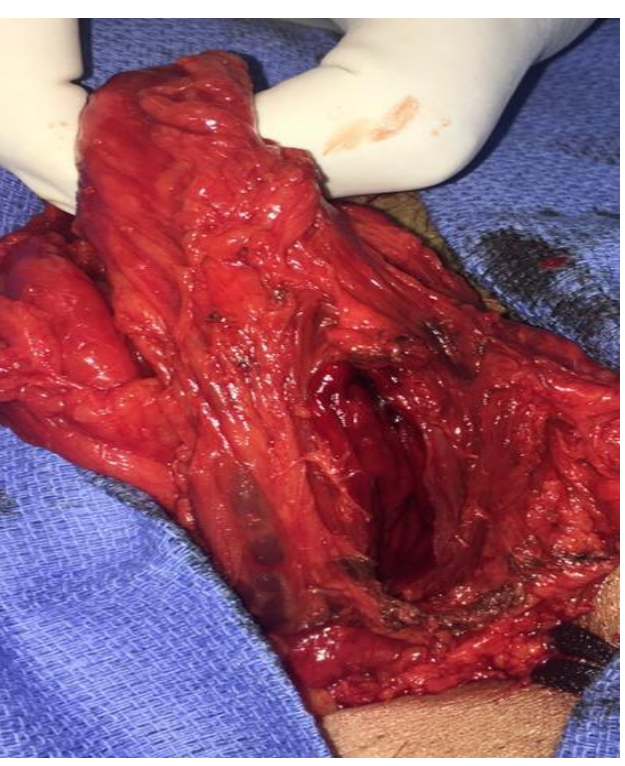

\section{DISCUSSION}

Bladder hernia is very rare and is usually asymptomatic [3]. It is most often diagnosed accidently during inguinal hernia repair, The most frequent finding is a two-phase micturition.[4] Other clinical findings include scrotal mass, difficulty in micturition, and fluctuation in the herniated mass during micturition [5].

Several factors may contribute to the development of inguinal bladder hernia including bladder outlet obstruction [6], weakness of pelvic musculature, decreased bladder tone, and obesity [7]. Risk factors include male gender, advanced age, and benign prostatic hyper-trophy [8].

Previous reports have described other rare cases including patients presenting with massive bladder herniation resulting in acute renal failure [9], bilateral hydronephrosis [10, 11], inguinal bladder hernia masking bowel ischemia, and bladder hernia with ureteral obstruction years after kidney transplantation [11].

The diagnosis is made clinically, with history, physical examination, intravenous pyelography (IVP), cystography [12], or during inguinal operation [13].

Retrograde cystography is the radiological modality with the highest diagnostic value [14]. Typical radiological findings include abnormal localization of the herniated structures and asymmetry [15], protrusion of the ureter outside the pelvic bones, and the indentation of the bladder wall [16]. Retrograde pyelography can be performed in cases where ureters are also in the hernial contents [17].

The preoperative diagnosis of bladder herniations is important to prevent the possible iatrogenic trauma that can occur during surgery [18].
Catheterisation may also reduce the size of the hernia, nocturia, dysuria, and hematuria may be related to the bladder outlet obstruction [18], or secondary infection can accompanies that condition.

Cianco et al., reported that only $7 \%$ of the patients in their series had preoperative diagnosis, and $16 \%$ of the patients had the diagnosis after postoperative complications occurred [19]. As a result, for all patients older than 50 years of age for whom inguinal hernia repair is being planned, preoperative exclusion of this pathology should be made [20].

In conclusion, urinary bladder can herniate into the inguinal canal even though this pathology is rare. The preoperative diagnosis is important to prevent complications [21]. Although the conventional modalities are successful in making the diagnosis, CT can be an important aid in diagnosis [21].

\section{REFERENCES}

1. De Angelis, M., Mantovani, G., Di Lecce, F., \& Boccia, L. (2018). Inguinal bladder and ureter hernia permagna: definition of a rare clinical entity and case report. Case reports in surgery, 2018.

2. Mohan, A., \& Srinivasan, K. (2017). Scrotal cystocele in a sliding left inguinoscrotal hernia: A case report and review of literature. Euroasian journal of hepato-gastroenterology, 7(1), 87.

3. Moufid, K., Touiti, D., \& Mohamed, L. (2013). Inguinal bladder hernia: four case analyses. Reviews in urology, 15(1), 32-36.

4. Taskovska, M., \& Janež, J. (2017). Inguinal hernia containing urinary bladder-a case report. International journal of surgery case reports, 40, 36-38.

5. Agha, R. A., Borrelli, M. R., Farwana, R., Koshy, K., Fowler, A., \& Orgill, D. P. (2018). For the SCARE Group, The SCARE 2018 statement: updating consensus Surgical Case Report (SCARE) guidelines, Int J Surg, 60, 132-136.

6. Ugur, M., Atc1, N., Oruc, C., Akkucuk, S., \& Aydogan, A. (2016). Left inguinal bladder herniathat causes dilatation in the ureter, Arch Iran Med, 19(5), 376-378.

7. Wagner, A. A., Arcand, P., \& Bamberger, M. H. (2004). Acute renal failure resulting from huge inguinal bladder hernia. Urology, 64(1), 156-157.

8. Habib, A. (2017). A rare case of inguinal hernia with complete bladder herniation. Case reports in surgery, 2017.

9. Çalışkan, S., Türkmen, M., \& Sungur, M. (2018). Inguinal bladder hernia in female patient. Iranian journal of medical sciences, 43(6), 671-672.

10. Ghielmini, E., Julita, L., Cerantola, Y., Matter, M., \& Zingg, T. (2017, September). Inguinal bladder hernia with acute ureteral obstruction 14 years after kidney transplantation: A case report. In Transplantation proceedings (Vol. 49, No. 7, pp. 1593-1595). Elsevier. 
11. MM, M. C. (2000). Ultrasonographic diagnosis of massive bladder hernia at the inguinoscrotal level: report of a case. Actas urologicas espanolas, 24(10), 825-828.

12. Khan, K., Chaudhry, A., \& Feinman, M. B. (2016). Inguinoscrotal hernia containing the urinary bladder. Case Reports, 2016, bcr2016217408.

13. Ciancio, G., Burke, G. W., Nery, J., Huson, H., Coker, D., \& Miller, J. (1995). Positional obstructive uropathy secondary to ureteroneocystostomy herniation in renal transplant recipient. The Journal of urology, 154(4), 14711472.

14. De Angelis, M., Mantovani, G., Di Lecce, F., \& Boccia, L. (2018). Inguinal bladder and ureter hernia permagna: definition of a rare clinical entity and case report. Case reports in surgery, 2018.

15. Tan, G. Y., Guy, R. J., \& Eu, K. W. (2003). Obstructing sigmoid cancer with local invasion in an incarcerated inguinal hernia. ANZ journal of surgery, 73(1-2), 80-82.

16. Trakarnsagna, A., Chinswangwatanakul, V., Methasate, A., Swangsri, J., Phalanusitthepha, C., Parakonthun, T., ... \& Akaraviputh, T. (2014). Giant inguinal hernia: report of a case and reviews of surgical techniques. International journal of surgery case reports, 5(11), 868-872.
17. Agu, T. C., \& Ikeanusi, M. P. (2016). A giant inguinoscrotal hernia in the 21 st century urban Nigeria setting? A case report and review of the literature. The Nigerian Journal of General Practice, 14(2), 42-45.

18. Fai, A. C., Leung, A. K., \& Robson, W. L. M. (2007). Urinary bladder calculi in a sliding vesicalinguinal-scrotal hernia diagnosed preoperatively by plain abdominal radiography. Advances in therapy, 24(5), 1016-1019.

19. Durán Barquero, C., Serrano Vicente, J., García Bernardo, L., Domínguez Grande, M., Rayo Madrid, J., Infante De La Torre, J., \& Sánchez Sánchez, R. (2010). Herniación inguinal de un divertículo vesical, diagnosticada con PETTAC. Revista Española de Medicina Nuclear e Imagen Molecular, 29(1), 36-37.

20. Shizukuishi, T., Abe, K., Takahashi, M., Sakaguchi, M., Aizawa, T., Narata, M., ... \& Furuhashi, S. (2009). Inguinal Bladder Hernia: Multi-Planar Reformation And 3-D Reconstruction Computed Tomography Images Useful For Diagnosis. Nephrology, 14(2), 263.

21. Goyal, S., Shrivastva, M., Verma, R. K., \& Goyal, S. (2015). "Uncommon Contents of Inguinal Hernial Sac": A Surgical Dilemma. Indian Journal of Surgery, 77(2), 305-309. 